\title{
g-Functions for bore fields with mixed parallel and series connections considering axial fluid temperature variations
}

\section{Massimo Cimmino}

\begin{abstract}
A semi-analytical method based on the finite line source (FLS) solution is presented to evaluate thermal response factors for geothermal bore fields with mixed series and parallel connections between boreholes. Each borehole in the bore field is modelled as a series of finite line source segments. The spatial and temporal superposition of the FLS solution for all pairs of segments in the bore field gives the total temperature change at the wall of the borehole segments. The axial variation of heat extraction rates is evaluated from the borehole wall temperatures using a steady-state analytical model of the fluid temperature variations inside the boreholes, considering the piping configuration to determine the inlet fluid temperature into a borehole from the inlet fluid temperature into the bore field. The concept of effective bore field thermal resistance is introduced to relate the arithmetic mean fluid temperature in a bore field, the average heat extraction rate per unit borehole length and a newly introduced effective borehole wall temperature. The g-function of a bore field with mixed series and parallel connections between boreholes is then defined from the effective borehole wall temperature, rather than the average borehole wall temperature.
\end{abstract}

\section{INTRODUCTION}

Simulation and design methods for geothermal systems often make use of thermal response factors - or $\mathrm{g}$-functions. When superimposed in time, $\mathrm{g}$-functions give the variation of ground temperatures due to varying heat extraction rates from the bore field. Originally, thermal response factors for bore fields were evaluated numerically (Eskilson, 1987). Since then, analytical methods based on the finite line source solution have been developed to evaluate g-functions (Zeng et al., 2002; Lamarche and Beauchamp, 2007; Claesson and Javed, 2011; Cimmino and Bernier, 2014; Lazzarotto, 2016). In analytical methods, boreholes are generally considered to be connected in parallel. Marcotte and Pasquier (2014) developed a method to account for piping connections between boreholes by including the borehole thermal resistance in their formulation. Their method, however, did not consider the axial variation of fluid temperatures, borehole wall temperatures and heat extraction rates. Previous work has shown that axial variation of heat extraction rates have an important impact on the long-term ground temperature variations (Cimmino and Bernier, 2014; Cimmino, 2015). The present paper represents improvements over previous works. In Cimmino (2015), $\mathrm{g}$-functions were calculated for single U-tube boreholes connected in parallel. In Cimmino (2016), fluid and borehole wall temperature profiles were calculated for a single borehole with multiple U-tubes. In the present work, $g$-functions 
are calculated for boreholes - with potentially multiple U-tubes - in any configuration of parallel and series connections between boreholes. While series-connected boreholes are not common in ground-source heat pump systems, they are useful in ground thermal energy storage applications.

\section{MATHEMATICAL MODEL}

The g-function of a geothermal bore field gives the relation between the rate of heat extraction and the borehole wall temperature change:

$$
\bar{T}_{b}\left(t_{k}\right)=T_{0}-g\left(t_{k}\right) \frac{\bar{Q}_{b}^{\prime}}{2 \pi k_{s}}
$$

where $\bar{T}_{b}$ is the average borehole wall temperature, $T_{0}$ is the undisturbed ground temperature, $\bar{Q}_{b}^{\prime}$ is the average heat extraction rate per unit borehole length, $k_{s}$ is the ground thermal conductivity and $g$ is the g-function.

A field of 3 boreholes is presented in Figure 1. Each borehole $i$ has a length $L_{i}$, is buried at a distance $D_{i}$ from the ground surface, and is positioned at coordinates $\left(x_{i}, y_{i}\right)$ on the ground surface. All boreholes have the same radius $r_{b}$. In the context of the present paper, boreholes may be connected in mixed configurations of series and parallel piping connections between boreholes. In Figure 1, the outlet of borehole 1 is connected to the inlet of borehole 2. The circuit composed of boreholes 1 and 2 is in parallel with borehole 3: fluid is fed at the inlet fluid temperature $T_{f, i n}$ to boreholes 1 and 3 and the outlet fluid temperature of the bore field $T_{f, \text { out }}$ is the mix of the fluid exiting boreholes 2 and 3.

\section{Thermal response factor with mixed inlet fluid temperature conditions}

g-Functions are evaluated by simultaneously solving 3 sets of equations: (1) the superposition of the FLS solution, (2) the global energy balance, and (3) the fluid temperature variations inside boreholes.

Superposition of the finite line source solution. Each borehole $i$ in the bore field is modelled as a series of $n_{q, i}$ borehole segments of equal length $L_{i} / n_{q, i}$. The temperature along any segment in the bore field is obtained by summing the temperature variations caused by all segments in the bore field. The spatial and temporal superpositions of the FLS solution is given by:

$$
\begin{gathered}
\boldsymbol{T}_{\boldsymbol{b}}\left(t_{k}\right)=\boldsymbol{T}_{\boldsymbol{b}, \mathbf{0}}\left(t_{k}\right)-\boldsymbol{H}\left(\Delta t_{k}\right) \frac{\boldsymbol{Q}_{\boldsymbol{b}}^{\prime}\left(t_{k}\right)}{2 \pi k_{s}} \\
\boldsymbol{T}_{\boldsymbol{b}, \mathbf{0}}\left(t_{k}\right)=T_{0}-\sum_{p=1}^{k-1}\left[\boldsymbol{H}\left(t_{k}-t_{p-1}\right)-\boldsymbol{H}\left(t_{k}-t_{p}\right)\right] \boldsymbol{Q}_{\boldsymbol{b}}^{\prime}\left(t_{p}\right) / 2 \pi k_{s}
\end{gathered}
$$

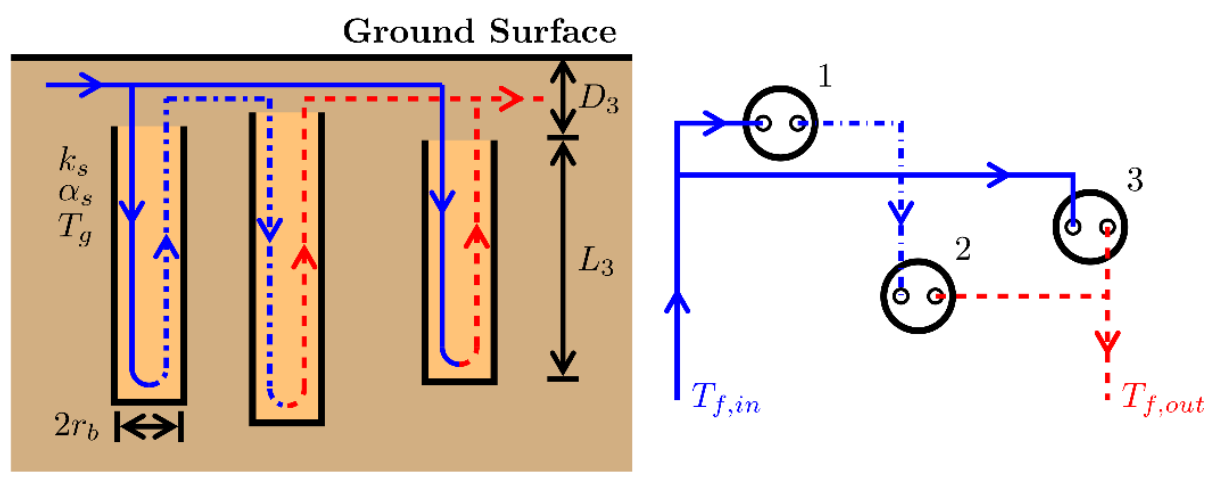

Figure 1 Boreholes in a mixed parallel-series configuration: side view (left) and top view (right) 
where $\boldsymbol{T}_{\boldsymbol{b}}=\left[\begin{array}{lll}\boldsymbol{T}_{\boldsymbol{b}, \mathbf{1}}^{\boldsymbol{T}} & \cdots & \boldsymbol{T}_{\boldsymbol{b}, \boldsymbol{N}_{\boldsymbol{b}}}^{\boldsymbol{T}}\end{array}\right]^{\boldsymbol{T}}$ is a $N_{q} \times 1$ vector of the borehole wall temperatures along all segments of all boreholes, $\boldsymbol{T}_{\boldsymbol{b}, \boldsymbol{i}}=\left[\begin{array}{lll}T_{b, i, 1} & \cdots & T_{b, i, n_{q, i}}\end{array}\right]^{\boldsymbol{T}}$ is a $n_{q, i} \times 1$ vector of the borehole wall temperatures along all segments of a borehole $i, \boldsymbol{T}_{\boldsymbol{b}, \mathbf{0}}\left(t_{k}\right)$ is a $N_{q} \times 1$ vector of the borehole wall temperatures along all segments of all boreholes assuming $\boldsymbol{Q}_{\boldsymbol{b}}^{\prime}\left(t_{k}\right)=0, \boldsymbol{Q}_{\boldsymbol{b}}^{\prime}=\left[\begin{array}{lll}\boldsymbol{Q}_{\boldsymbol{b}, \mathbf{1}}^{\prime \boldsymbol{T}} & \cdots & \boldsymbol{Q}_{\boldsymbol{b}, \boldsymbol{N}_{\boldsymbol{b}}}^{\prime \boldsymbol{T}}\end{array}\right]^{\boldsymbol{T}}$ is a $N_{q} \times 1$ vector of the heat extraction rates per borehole length along all segments of all boreholes, $\boldsymbol{Q}_{\boldsymbol{b}, \boldsymbol{i}}^{\prime}=\left[\begin{array}{lll}Q_{b, i, 1}^{\prime} & \cdots & Q_{b, i, n_{q, i}}^{\prime}\end{array}\right]^{\boldsymbol{T}}$ is a $n_{q, i} \times 1$ vector of the heat extraction rates per borehole length along all segments of a borehole $i, \boldsymbol{H}$ is a $N_{q} \times N_{q}$ matrix of segment-to-segment thermal response factors, $N_{q}=$ $\sum_{i=1}^{N_{b}} n_{q, i}$ is the total number of segments in the bore field. The thermal response factor matrix is built from the FLS solution for all pairs of borehole segments. From Cimmino and Bernier (2014):

$$
\begin{gathered}
h_{i j, u v}\left(t_{k}\right)=\frac{1}{2 L_{i, u}} \int_{1 / \sqrt{4 \alpha_{s} t_{k}}}^{\infty} \frac{1}{s^{2}} \exp \left(-d_{i j}^{2} s^{2}\right) I_{F L S}(s) d s \\
I_{F L S}(s)=\operatorname{erfint}\left(\left(D_{i, u}-D_{j, v}+L_{i, u}\right) s\right)-\operatorname{erfint}\left(\left(D_{i, u}-D_{j, v}\right) s\right)+\operatorname{erfint}\left(\left(D_{i, u}-D_{j, v}-L_{j, v}\right) s\right)- \\
\operatorname{erfint}\left(\left(D_{i, u}-D_{j, v}+L_{i, u}-L_{j, v}\right) s\right)+\operatorname{erfint}\left(\left(D_{i, u}+D_{j, v}+L_{i, u}\right) s\right)-\operatorname{erfint}\left(\left(D_{i, u}+D_{j, v}\right) s\right)+ \\
\operatorname{erfint}\left(\left(D_{i, u}+D_{j, v}+L_{j, v}\right) s\right)-\operatorname{erfint}\left(\left(D_{i, u}+D_{j, v}+L_{i, u}+L_{j, v}\right) s\right)
\end{gathered}
$$

where $h_{i j, u v}$ is the segment-to-segment thermal response factor on segment $u$ of borehole $i$ from heat extraction at segment $v$ of borehole $j, L_{i, u}=L_{i} / n_{q, i}$ is the length of segment $u$ of borehole $i, D_{i, u}=D_{i}+(u-1) L_{i} / n_{q, i}$ is the buried depth of segment $u$ of borehole $i, d_{i j}$ is the distance between boreholes $i$ and $j, d_{i i}=r_{b}, \alpha_{s}$ is the ground thermal diffusivity, and $\operatorname{erfint}(x)=x \cdot \operatorname{erf}(x)-\frac{1}{\sqrt{\pi}}\left(1-\exp \left(-x^{2}\right)\right)$ is the integral of the error function.

Global energy balance. The total heat extraction rate in the bore field is equal to the sum of the heat extraction rates along all segments of all boreholes:

$$
\boldsymbol{L} \boldsymbol{Q}_{\boldsymbol{b}}^{\prime}\left(t_{k}\right)=Q_{b, t o t}
$$

where $\boldsymbol{L}=\left[\begin{array}{lll}\boldsymbol{L}_{1} & \cdots & \boldsymbol{L}_{\boldsymbol{N}_{\boldsymbol{b}}}\end{array}\right]$ is a $1 \times N_{q}$ vector of the lengths of all segments of all boreholes, $\boldsymbol{L}_{\boldsymbol{i}}=$ $\left[\begin{array}{lll}L_{i, 1} & \cdots & L_{i, n_{q, i}}\end{array}\right]$ is a $1 \times n_{q, i}$ vector of the lengths of all segments of borehole $i$ and $Q_{b, t o t}$ is the total heat extraction rate in the bore field. From Equation (1), for $Q_{b, t o t}=2 \pi k_{s} L_{t o t}$, the average borehole wall temperature is equal to the g-function of the bore field.

Fluid temperature variations. Assuming steady-state heat transfer between the fluid circulating in a borehole $i$ and its borehole wall, the fluid temperature variations in the borehole are given by the following system of differential equations (Cimmino, 2016):

$$
\frac{\partial \boldsymbol{T}_{f, i}}{\partial z}(z)=\boldsymbol{S}_{\boldsymbol{i}} \boldsymbol{T}_{f, i}(z)-\boldsymbol{S}_{\boldsymbol{i}} \mathbf{1}_{2 n_{p, i} \times 1} T_{b, i}(\mathrm{z}), 0 \leq z \leq L_{i}
$$

where $\boldsymbol{T}_{\boldsymbol{f}, \boldsymbol{i}}$ is a $2 n_{p, i} \times 1$ vector of fluid temperatures in each pipe of borehole $i$, and $\boldsymbol{S}_{\boldsymbol{i}}$ is a $2 n_{p, i} \times 2 n_{p, i}$ built from the delta-circuit of internal thermal resistances in borehole $i$, considering the fluid mass flow rate inside the pipes. $n_{p, i}$ is the number of pipe pairs in borehole $i . \mathbf{1}_{2 n_{p, i} \times 1}$ is a $2 n_{p, i} \times 1$ matrix of ones.

The solution to the system of differential equations, assuming uniform borehole wall temperatures along the borehole segments, is given by: 


$$
\begin{gathered}
\boldsymbol{T}_{\boldsymbol{f}, \boldsymbol{i}}(\mathrm{z})=\operatorname{expm}\left(\boldsymbol{S}_{\boldsymbol{i}} \mathrm{z}\right) \boldsymbol{T}_{\boldsymbol{f}, \boldsymbol{i}}(0)-\boldsymbol{F}_{\boldsymbol{i}}(\mathrm{z}) \boldsymbol{T}_{\boldsymbol{b}, \boldsymbol{i}} \\
\boldsymbol{F}_{\boldsymbol{i}}(\mathrm{z})=\left[\begin{array}{lll}
\boldsymbol{F}_{\boldsymbol{i}, \mathbf{1}}(\mathrm{z}) & \cdots & \boldsymbol{F}_{\boldsymbol{i}, \boldsymbol{n}_{\boldsymbol{q}, \boldsymbol{i}}}(\mathrm{z})
\end{array}\right] \\
\boldsymbol{F}_{i, \boldsymbol{u}}(\mathrm{z})=\boldsymbol{S}_{\boldsymbol{i}}^{-\mathbf{1}}\left[\operatorname{expm}\left(\boldsymbol{S}_{\boldsymbol{i}} \max \left(0, \mathrm{z}-\frac{(u-1) L_{i}}{n_{q, i}}\right)\right)-\operatorname{expm}\left(\boldsymbol{S}_{\boldsymbol{i}} \max \left(0, \mathrm{z}-\frac{u L_{i}}{n_{q, i}}\right)\right)\right] \boldsymbol{S}_{\boldsymbol{i}} \mathbf{1}_{2 n_{p, i} \times 1}
\end{gathered}
$$

where $\boldsymbol{F}_{\boldsymbol{i}}$ is a $2 n_{p, i} \times n_{q, i}$ matrix of coefficients and $\operatorname{expm}(\boldsymbol{X})$ is the matrix exponential.

For boreholes with any amount of U-tubes connected in series or in parallel, the outlet fluid temperature and the heat extraction rates along the borehole segments can be expressed in terms of the inlet fluid temperature and the borehole wall temperature along the borehole segments:

$$
\begin{aligned}
T_{f, \text { out }, i} & =a_{\text {out }, i} T_{f, \text { in }, i}+\boldsymbol{b}_{\text {out }, i} \boldsymbol{T}_{\boldsymbol{b}, \boldsymbol{i}} \\
\boldsymbol{Q}_{\boldsymbol{b}, \boldsymbol{i}} & =\boldsymbol{a}_{\boldsymbol{Q}, \boldsymbol{i}} T_{f, \text { in }, i}+\boldsymbol{b}_{\boldsymbol{Q}, \boldsymbol{i}} \boldsymbol{T}_{\boldsymbol{b}, \boldsymbol{i}}
\end{aligned}
$$

where $T_{f, i n, i}$ and $T_{f, o u t, i}$ are the inlet and outlet fluid temperatures of borehole $i, \boldsymbol{Q}_{\boldsymbol{b}, i}=\left[\begin{array}{lll}Q_{b, i, 1} & \cdots & Q_{b, i, n_{q, i}}\end{array}\right]^{\boldsymbol{T}}$ is a $n_{q, i} \times 1$ vector of the heat extraction rates along all segments of a borehole $i, a_{\text {out }, i}$ is a coefficient, and $\boldsymbol{b}_{\text {out }, \boldsymbol{i}}, \boldsymbol{a}_{\boldsymbol{Q}, \boldsymbol{i}}$ and $\boldsymbol{b}_{Q, i}$ are $1 \times n_{q, i}, n_{q, i} \times 1$ and $n_{q, i} \times n_{q, i}$ vectors and matrices of coefficients. Expressions for the coefficients are given by Cimmino (2016).

By considering the connections between the boreholes in the bore field, Equations (11) and (12) can be rewritten in terms of the inlet fluid temperature into the bore field:

$$
\begin{gathered}
T_{f, \text { out }, i}=A_{\text {out }, i} T_{f, \text { in }}+\sum_{j \in P_{i}} \boldsymbol{B}_{\text {out }, i, j} \boldsymbol{T}_{\boldsymbol{b}, j} \\
A_{\text {out }, i}=\prod_{k \in P_{i}} a_{\text {out }, k}, \quad \boldsymbol{B}_{\text {out }, i, j}=\left(\prod_{\substack{k \in P_{i} \\
k \notin P_{j}}} a_{\text {out }, k}\right) \boldsymbol{b}_{\text {out }, j}
\end{gathered}
$$

where $T_{f, i n}$ is the inlet fluid temperature into the bore field, $A_{\text {out }, i}$ is a coefficient, $\boldsymbol{B}_{\boldsymbol{o u t}, \boldsymbol{i}, \boldsymbol{j}}$ is a $1 \times n_{q, i}$ vector of coefficients and $P_{i}$ is the path from borehole $i$ to the field inlet. The path $P_{i}$ is the list of boreholes that connect the borehole $i$ to the field inlet, starting from borehole $i$. As an example, the paths of the boreholes identified on Figure 1 are $P_{1}=\{1\}, P_{2}=\{2,1\}$ and $P_{3}=\{3\}$. $\prod$ is the product operator, with $\prod_{k \in\{1,2,3\}} a_{k}=a_{1} a_{2} a_{3}$.

Coefficients for the heat extraction rates are obtained in the same manner:

$$
\begin{gathered}
\boldsymbol{Q}_{\boldsymbol{b}, \boldsymbol{i}}=\boldsymbol{A}_{Q, i} T_{f, \text { in }}+\sum_{j \in P_{i}} \boldsymbol{B}_{Q, i, j} \boldsymbol{T}_{\boldsymbol{b}, \boldsymbol{j}} \\
\boldsymbol{A}_{Q, i}=\boldsymbol{a}_{Q, i}\left(\prod_{\substack{k \in P_{i} \\
k \neq i}} a_{\text {out }, k}\right), \boldsymbol{B}_{Q, i, j}=\left(\prod_{\substack{k \in P_{i} \\
k \notin P_{j}}} a_{o u t, k}\right) \boldsymbol{b}_{Q, j}
\end{gathered}
$$

where $\boldsymbol{A}_{\boldsymbol{Q}, \boldsymbol{i}}$ is a $n_{q, i} \times 1$ vector of coefficients and $\boldsymbol{B}_{\boldsymbol{Q}, \boldsymbol{i}, \boldsymbol{j}}$ is a $n_{q, i} \times n_{q, i}$ matrix of coefficients.

System of equations. Equations (2), (6) and (15) form a system of equations that relate the heat extraction rates along all segments of all boreholes, the borehole wall temperatures along all segments of all boreholes and the inlet fluid temperature into the bore field. The system of equation can be solved sequentially to evaluate the $g$-function of a bore 
field at all times $t_{k}$. The system of equations is given by:

$$
\begin{gathered}
{\left[\begin{array}{ccc}
\boldsymbol{H} / 2 \pi k_{s} & -\boldsymbol{I}_{N_{q}} & \mathbf{0}_{N_{q} \times 1} \\
-\boldsymbol{I}_{N_{q}} & \boldsymbol{B}_{\boldsymbol{Q}} & \boldsymbol{A}_{\boldsymbol{Q}} \\
\boldsymbol{L} & \mathbf{0}_{1 \times N_{q}} & \mathbf{0}_{1 \times N_{q}}
\end{array}\right]\left[\begin{array}{c}
\boldsymbol{Q}_{\boldsymbol{b}}^{\prime} \\
\boldsymbol{T}_{\boldsymbol{b}} \\
T_{f, i n}
\end{array}\right]=\left[\begin{array}{c}
-\boldsymbol{T}_{\boldsymbol{b}, \mathbf{0}} \\
\mathbf{0}_{N_{q} \times 1} \\
Q_{b, t o t}
\end{array}\right]} \\
\boldsymbol{A}_{\boldsymbol{Q}}=\left[\begin{array}{lll}
\boldsymbol{A}_{\boldsymbol{Q}, \mathbf{1}}^{T} & \cdots & \boldsymbol{A}_{\boldsymbol{Q}, \boldsymbol{N}_{\boldsymbol{b}}}^{T}
\end{array}\right]^{\boldsymbol{T}}, \boldsymbol{B}_{\boldsymbol{Q}}=\left[\begin{array}{ccc}
\boldsymbol{B}_{\boldsymbol{Q}, \mathbf{1 , 1}} & \cdots & \boldsymbol{B}_{\boldsymbol{Q}, \boldsymbol{N}_{b}, \mathbf{1}} \\
\vdots & \ddots & \vdots \\
\boldsymbol{B}_{\boldsymbol{Q}, N_{b}, \mathbf{1}} & \cdots & \boldsymbol{B}_{\boldsymbol{Q}, N_{b}, N_{b}}
\end{array}\right]
\end{gathered}
$$

\section{Effective borehole wall temperature}

During simulation of ground-source heat pump systems, the mean fluid temperature in a borehole is commonly expressed in terms of the average borehole wall temperature and the effective borehole thermal resistance:

$$
\bar{T}_{f}=\frac{1}{2}\left(T_{f, \text { in }}+T_{f, \text { out }}\right)=\bar{T}_{b}-\bar{Q}_{b}^{\prime} R_{b}^{*}
$$

where $R_{b}^{*}$ is the effective borehole thermal resistance.

However, in bore fields that include series connections between boreholes, it is possible for the arithmetic mean fluid temperature in the field to be lower than the average borehole wall temperature during heat extraction. This makes Equation (19) impossible to apply in these cases and necessitates the introduction of the concept of effective borehole wall temperature to replace the average borehole wall temperature in the definition of the g-function. The effective borehole wall temperature will be defined from an effective bore field thermal resistance.

Effective borehole termal resistance. Based on the work of Hellström (1991), an effective borehole thermal resistance can be calculated by assuming a uniform temperature along the length of the borehole. Equations (11) and

(12) are then simplified by considering the fluid temperature differences $\theta_{f, \text { out }, i}=T_{f, \text { out }, i}-\bar{T}_{b, i}$ and $\theta_{f, i n, i}=T_{f, \text { in }, i}-$ $\bar{T}_{b, i}$, where $\bar{T}_{b, i}$ is the uniform borehole wall temperature along borehole $i$ :

$$
\theta_{f, \text { out }, i}=a_{\text {out }, i} \theta_{f, \text { in }, i}, \boldsymbol{Q}_{\boldsymbol{b}, \boldsymbol{i}}=\boldsymbol{a}_{\boldsymbol{Q}, i} \theta_{f, \text { in }, i}
$$

The effective borehole resistance is calculated based on the arithmetic mean fluid temperature:

$$
\begin{gathered}
R_{b, i}^{*}=-\frac{\bar{\theta}_{f, i}}{\bar{Q}_{b, i}^{\prime},} \bar{\theta}_{f, i}=\frac{1}{2}\left(\theta_{f, \text { in }, i}+\theta_{f, \text { out }, i}\right), \bar{Q}_{b, i}^{\prime}=\mathbf{1}_{1 \times n_{q, i}} \boldsymbol{Q}_{b, i} / L_{i} \\
R_{b, i}^{*}=-\left(\frac{1+a_{o u t, i}}{\mathbf{1}_{1 \times n_{q, i}} \boldsymbol{a}_{Q, i}}\right) \frac{L_{i}}{2}
\end{gathered}
$$

Effective bore field termal resistance. The same process is applied to define an effective bore field termal resistance and an effective borehole wall temperature. The outlet fluid temperature difference from the bore field is obtained from an energy balance:

$$
\theta_{f, \text { out }}=A_{\text {out }} \theta_{f, \text { in }}, A_{\text {out }}=1+\mathbf{1}_{1 \times N_{q}} \cdot \boldsymbol{A}_{\boldsymbol{Q}} /\left(\dot{m} c_{p}\right)
$$

The effective bore field termal resistance is then calculated based on the mean fluid temperature in the bore field: 


$$
R_{\text {field }}^{*}=-\left(\frac{1+A_{\text {out }}}{1_{1 \times N_{q} \cdot A_{Q}}}\right) \frac{L_{\text {tot }}}{2}, \bar{T}_{b}^{*}=\frac{1}{2}\left(T_{f, \text { in }}+T_{f, \text { out }}\right)+R_{\text {field }}^{*} \bar{Q}_{b}^{\prime}
$$

where $R_{\text {field }}^{*}$ is the effective bore field thermal resistance and $\bar{T}_{b}^{*}$ is the effective borehole wall temperature. This temperature replaces the average borehole wall temperature to evaluate the $\mathrm{g}$-function values.

\section{RESULTS}

The $\mathrm{g}$-function of a field of 5 series-connected boreholes of unequal lengths is evaluated. All boreholes have a radius $r_{b}=0.075 \mathrm{~m}$, are buried at a depth $D=4 \mathrm{~m}$ and are positioned on a straight line with an even spacing of $7.5 \mathrm{~m}$. Each borehole contains a single U-tube with pipes of inner radius $r_{p, \text { in }}=0.015 \mathrm{~m}$ and outter radius $r_{p, \text { out }}=0.020 \mathrm{~m}$, positioned symmetrically at a shank spacing of $0.050 \mathrm{~m}$. The pipe thermal conductivity is $k_{p}=0.4 \mathrm{~W} / \mathrm{m}-\mathrm{K}$, the grout thermal conductivity is $k_{g}=1.0 \mathrm{~W} / \mathrm{m}-\mathrm{K}$, the ground thermal conductivity is $k_{s}=2.0 \mathrm{~W} / \mathrm{m}-\mathrm{K}$ and the ground thermal diffusivity is $\alpha_{s}=10^{-6} \mathrm{~m}^{2} / \mathrm{s}$. The fluid mass flow rate per borehole is $\dot{m}_{f}=0.25 \mathrm{~kg} / \mathrm{s}$. The fluid specific heat capacity is $4000 \mathrm{~J} / \mathrm{kg}-\mathrm{K}$, its density is $1015 \mathrm{~kg} / \mathrm{m}^{3}$, its dynamic viscosity is $0.002 \mathrm{~kg} / \mathrm{m}$-s and its thermal conductivity is $k_{f}=0.5 \mathrm{~W} / \mathrm{m}-\mathrm{K}$. The borehole lengths, starting from the borehole connected to the bore field inlet, are $75 \mathrm{~m}, 100 \mathrm{~m}$, $125 \mathrm{~m}, 150 \mathrm{~m}$ and $75 \mathrm{~m}$. The bore field characteristic time $t_{s}=\frac{\bar{L}^{2}}{9 \alpha_{s}}$ is then 38.8 years.

The g-function of the series-connected boreholes and the temperature profiles at $\ln \left(t / t_{s}\right)=4.35$ $(t=3000$ years) are shown on Figure 2. Each of the g-functions were calculated in 26 seconds. The calculation of the $\mathrm{g}$-function involved the inversion of the matrix of Equation (17) at each of the 50 time steps. The matrix sizes were $61 \times 61$ and $121 \times 121$ for the uniform temperature and the mixed inlet temperature conditions, respectively. The $\mathrm{g}$-function of the series-connected boreholes is less than the $\mathrm{g}$-function using the uniform temperature condition: the $\mathrm{g}$-function value is 9.53 at $\ln \left(t / t_{s}\right)=4.35$ while it is 10.61 using the uniform temperature condition. This merely means that the effective borehole wall temperature is lower. As shown on Figure 2 (right), temperature variations vary between boreholes: the maximum dimensionless temperature change is 13.23 for the borehole located at the bore field inlet. Due to the effective bore field thermal resistance being larger than the effective borehole thermal resistance, the variations of mean fluid temperature will be larger in the case of series-connected boreholes. On Figure 2 (right), the dimensionless inlet and outlet fluid temperatures are 16.27 and 9.67. The bore field thermal resistance is $0.274 \mathrm{~m}-\mathrm{K} / \mathrm{W}$.
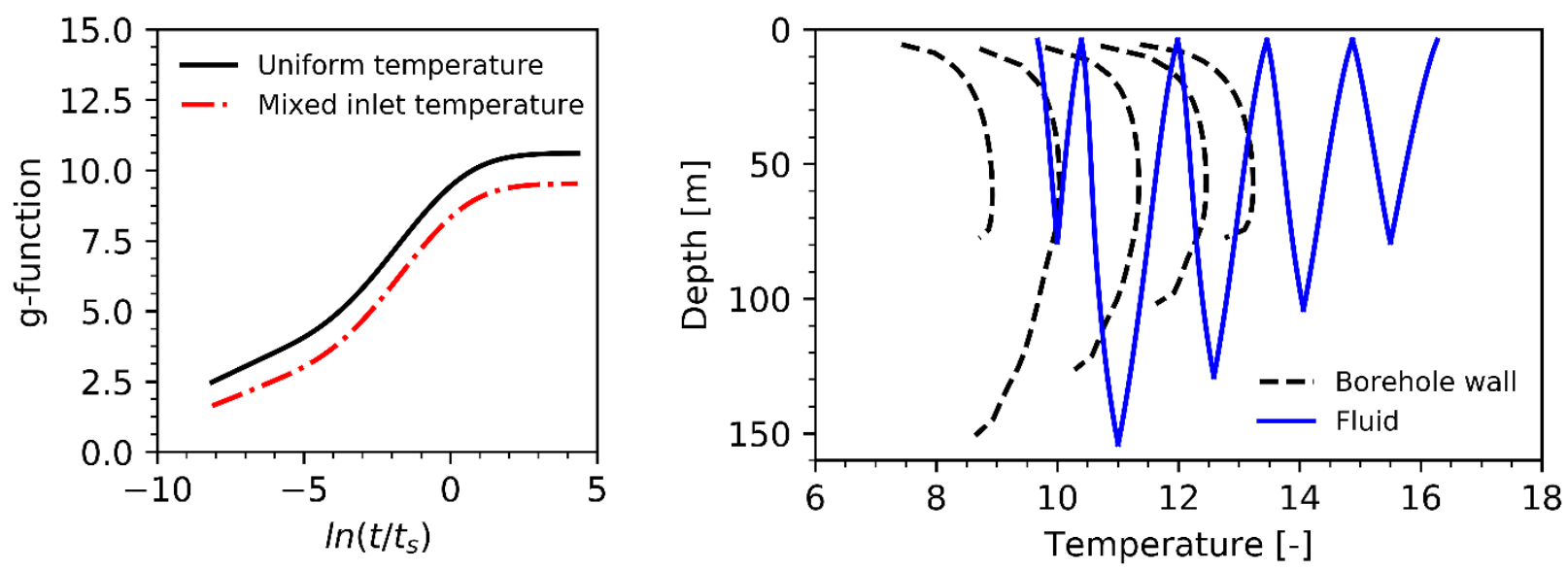

Figure 2 g-Function of 5 series-connected boreholes (left) and fluid and borehole wall temperatures at $\ln \left(t / t_{s}\right)=4.35$ (right) 
The effective bore field thermal resistance depends on both the bore field configuration and the fluid mass flow rate. Figure 3 shows the effective bore field thermal resistances of fields of 1, 3 and 5 series-connected boreholes at varying fluid mass flow rates. The thermal resistances are calculated for the same parameters as the previous example except the boreholes have equal lengths $L=150 \mathrm{~m}$. The effective bore field thermal resistance increases when boreholes are connected in series and decreases at larger fluid mass flow rates. At $\dot{m}_{f}=0.25 \mathrm{~kg} / \mathrm{s}$, the effective bore field thermal resistance is $0.141 \mathrm{~m}-\mathrm{K} / \mathrm{W}$ for a single borehole and $0.274 \mathrm{~m}-\mathrm{K} / \mathrm{W}$ for 5 series-connected boreholes. At a larger fluid mass flow rate $\dot{m}_{f}=1.0 \mathrm{~kg} / \mathrm{s}$, the effective bore field thermal resistances are closer: $0.135 \mathrm{~m}-\mathrm{K} / \mathrm{W}$ and $0.145 \mathrm{~m}-\mathrm{K} / \mathrm{W}$ for the single borehole and 5 series-connected boreholes, respectively.

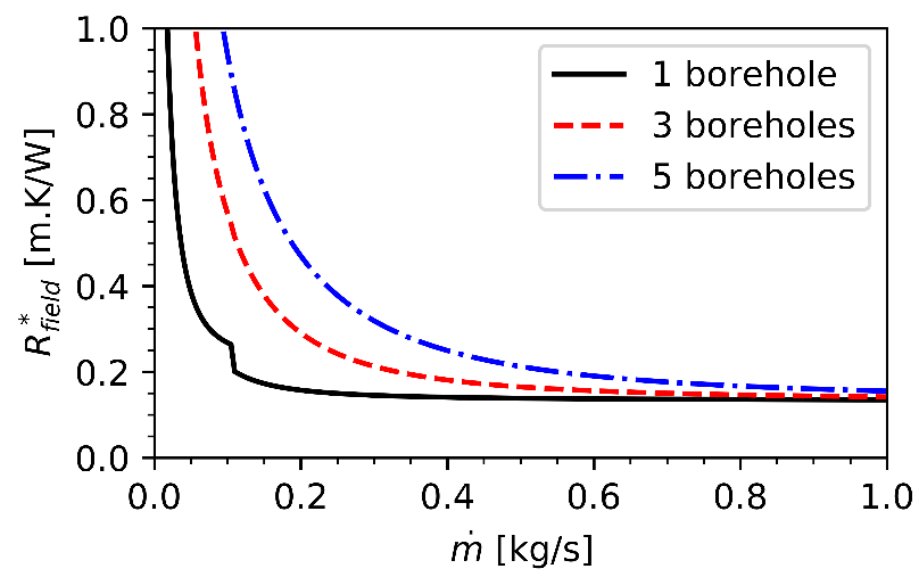

Figure 3 Effective bore field thermal resistance of series-connected boreholes

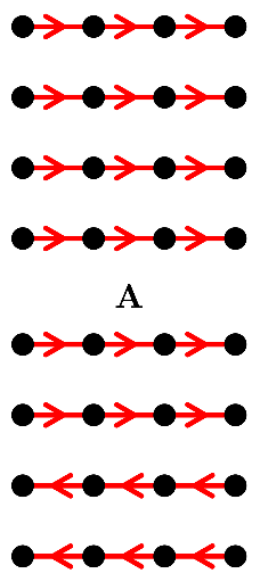

C

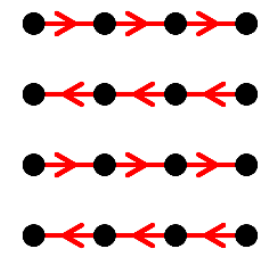

B

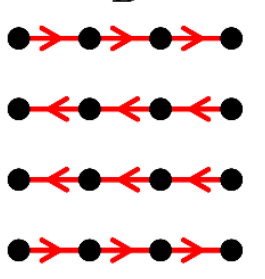

D
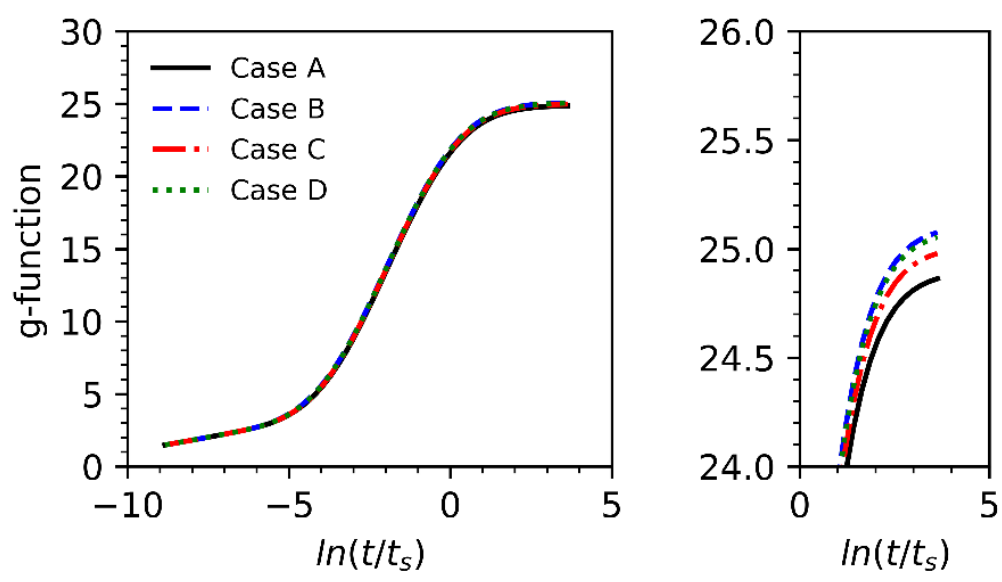

Figure 4 Field of $4 \times 4$ boreholes in mixed parallel-series configuration: piping network configurations (left), g-functions (center), and zoomed view (right) 
g-Functions can be used to compare different piping configurations for the same bore field. Figure 4 shows the $\mathrm{g}$-functions of 4 possible configurations of a field of $4 \times 4$ boreholes with 4 rows of 4 series-connected boreholes. The direction of flow in the rows is varied to evaluate its impact on the long-term temperature changes. All boreholes have the same length $L=150 \mathrm{~m}$ and receive the same fluid mass flow rate $\dot{m}_{f}=0.25 \mathrm{~kg} / \mathrm{s}$. It is shown that the direction of flow has little effect on the $g$-function. The $g$-function curves are very close, with the $g$-function of Case A having the lowest value and the $g$-function of Case B having the largest value. At $\ln \left(t / t_{s}\right)=3.63$ ( $t=3000$ years), the $g$-function values for Cases A and B are 24.86 and 25.08, respectively. In all cases, the bore field thermal resistance is $0.307 \mathrm{~m}-\mathrm{K} / \mathrm{W}$.

\section{CONCLUSION}

A semi-analytical method to evaluate the $\mathrm{g}$-function of bore fields with mixed series and parallel connections between boreholes is presented. Since both the borehole wall and fluid temperatures vary between boreholes, the $\mathrm{g}$-function needs to be defined based on the effective borehole wall temperature, rather than the average borehole wall temperature. The effective borehole wall temperature is in turn defined based on an effective bore field thermal resistance. The effective bore field thermal resistance is calculated by considering all boreholes to have the same uniform borehole wall temperature, equal to the effective borehole wall temperature. The method allows the evaluation of $\mathrm{g}$-functions of bore field with any number of boreholes of potentially different sizes, at any position, and with any piping configuration connecting the boreholes. The source code for the evaluation of $\mathrm{g}$-functions using this new method is available online (Cimmino 2018).

\section{ACKNOWLEDGMENTS}

The author received a start-up subsidy from the Fonds de recherche du Québec - Nature et Technologie (FRQNT).

\section{NOMENCLATURE}
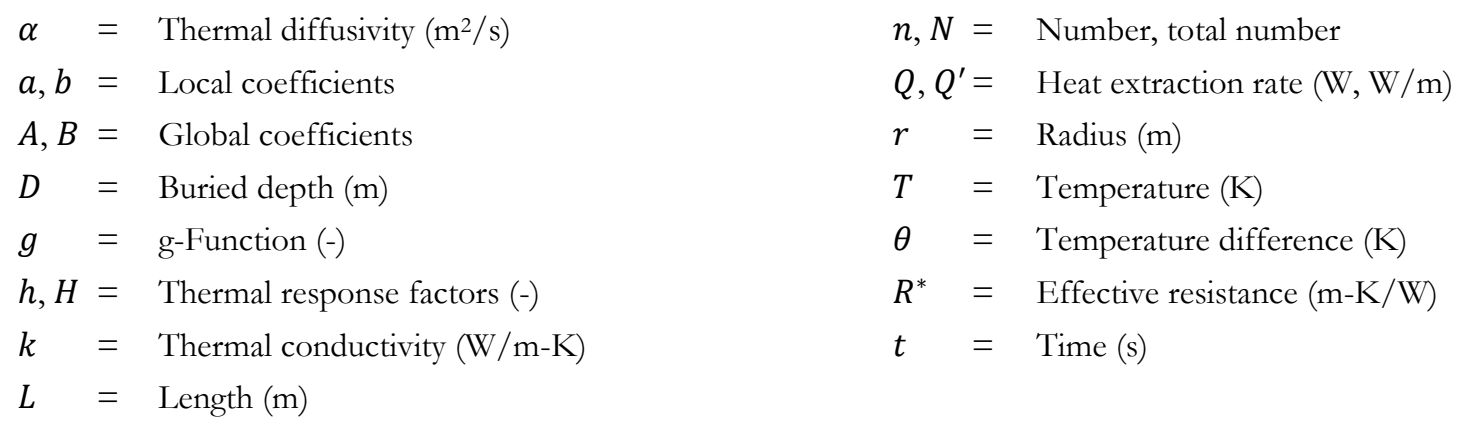

\section{Subscripts}

$0=$ No heat extraction

in, out $=$ Inlet, outlet

$b=$ Borehole

$f=$ Fluid

$q=$ Borehole segment

$g=$ Grout

\section{REFERENCES}

Cimmino, M. and M. Bernier. 2014. A semi-analytical method to generate g-functions for geothermal bore fields. International Journal of Heat and Mass Transfer 70(c): 641-650.

Cimmino, M. 2015. The effects of borehole thermal resistances and fluid flow rate on the g-functions of geothermal bore fields. International Journal of Heat and Mass Transfer 91: 1119-1127. 
Cimmino, M. 2016. Fluid and borehole wall temperature profiles in vertical geothermal boreholes with multiple U-tubes. Renewable Energy 96, Part A: 137-147.

Cimmino, M. 2018. MassimoCimmino/pygfunction V1.1.0. Zenodo. doi:10.5281/zenodo.1195039.

Claesson, J. and S. Javed. 2011. An analytical method to calculate borehole fluid temperatures for time-scales from minutes to decades. ASHRAE Transactions 117(2): 279-288.

Eskilson, P., 1987. Thermal Analysis of Heat Extraction Boreholes. Thesis (PhD), PhD Thesis, University of Lund, Sweden.

Hellström, G. 1991. Ground Heat Storage - Thermal Analyses of Duct Storage Systems - Theory. PhD Thesis, University of Lund, Sweden.

Lamarche, L. and B. Beauchamp. 2007. A new contribution to the finite line-source model for geothermal boreholes. Energy and Buildings 39(2): 188-198.

Lazzarotto, A. 2016. A methodology for the calculation of response functions for geothermal fields with arbitrarily oriented boreholes - Part 1. Renewable Energy 86: 1380-1393.

Marcotte D. and Pasquier P. 2014. Unit-response function for ground heat exchanger with parallel, series or mixed borehole arrangement. Renewable Energy. 68: 14-18.

Zeng, H. Y., N. R. Diao and Z. H. Fang. 2002. A finite line-source model for boreholes in geothermal heat exchangers. Heat Transfer Asian Research 31(7): 558-567. 